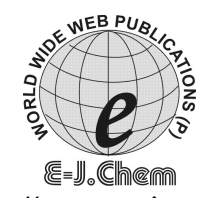

http://www.e-journals.net

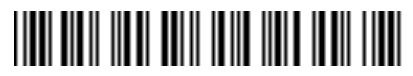

ISSN: 0973-4945; CODEN ECJHAO

E-Journal of Chemistry

Vol. 4, No. 4, pp. 574-580, October 2007

\title{
Interaction Studies of Dilute Aqueous Oxalic Acid
}

\author{
KIRAN KANDPAL, B.K.JOSHI*, S. K. JOSHI and N. D. KANDPAL \\ Physical Chemistry Laboratory, \\ Department of Chemistry Kumuan University, \\ S S J Campus Almora, U A 263601 (India), \\ bkjoshi_alm@rediffmail.com; narain_datt@rediffmail.com
}

Received 14 April 2007; Accepted 26 May 2007

\begin{abstract}
Molecular conductance $\lambda \mathrm{m}$, relative viscosity and density of oxalic acid at different concentration in dilute aqueous solution were measured at $293 \mathrm{~K}$. The conductance data were used to calculate the value association constant. Viscosity and density data were used to calculate the A and B coefficient of Jone-Dole equation and apparent molar volume respectively. The viscosity results were utilized for the applicability of Modified Jone-Dole equation and Staurdinger equations. Mono oxalate anion acts, as structure maker and the solute-solvent interaction were present in the dilute aqueous oxalic acid.
\end{abstract}

Keywords: Staurdinger equation, Modified Jone-Dole equation, Viscosity, Conductance, Oxalic acid

\section{Introduction}

Viscometric, volumetric and conductometric studies of a solute in case of aqueous solution is related to the interactions among the components of a solution ${ }^{1-3}$, a knowledge of which is important in solution chemistry. In highly dilute aqueous solutions, the two properties apparent molar volume and viscosity are needed to buildup such knowledge of inter molecular interactions.

The structural and dynamic nature of water molecules in different environments is also important in such aqueous solutions. Water it self is highly associated and its tendency to associate with solute molecule is high. The organic compound, which contains carboxyl group (name derived by linking carbonyl and hydroxyl), belongs to the class of carboxylic acid. These compounds have a capacity to form hydrogen bond like water. In this study viscometric, volumetric and conductometric studies of oxalic acid were undertaken to research the intermolecular/ionic interactions/structural features focused on highly dilute aqueous media. A survey of literature showed that there is lack of interaction studies of 
carboxylic acids in dilute aqueous solutions Moreover, carboxylic acids - water solvent system $^{4-6}$ and in water systems with other co-solute ${ }^{7-11}$ have been extensively used in the volumetric, viscometric or conductometric studies of salts of carboxylic acids.

Recently, studies relating to the measurement of partial molar volume of oxalic acid in aqueous solution ${ }^{12}$ and in aqueous solution of fructose have been reported ${ }^{11}$. In both the studies the data indicates the presence of storng solute-solvent/ion-solvent interactions. Such studies are still lacking in relation to viscosmetric and conductometric measurements in order to ascertain the various interactions present in dilute aqueous solutions. The study has been undertaken determination of the values of the coefficients $A_{x}$ and $B_{x}$ for modified Jone -Dole equation as proposed in our previous study ${ }^{1}$. The conductivity data has been measured under same experimental conditions and analyzed by the Arrhenius -Ostwald relation ${ }^{13}$.

\section{Experimental}

Deionised water was distilled twice with a small quantity of alkaline potassium permanganate. Finally water was distilled in corning glass apparatus with sulphuric acid. The specific conductance of prepared distilled water for the study was of the order. $2 \times 10^{-6} \Omega \mathrm{cm}^{-1}$ oxalic acid (GR Sarabhai M) was used as such and solutions were prepared by dissolving the calculated weight of the sample for desired strength in distilled water.

Density measurements of solutions were made using Pyknometer having capacity $15 \mathrm{~cm}^{3}$. Pyknometer was calibrated with distilled water having densities $0.9972 \mathrm{gm} \mathrm{cm}^{-3}$ and $0.9942 \mathrm{gm} \mathrm{cm}^{-3}$ at $298 \mathrm{~K}$ and $308 \mathrm{~K}$ respectively. The densities of solutions were determined from the mass of solution in the pyknometer after reaching thermal equilibrium with a thermostatically controlled water bath capable of maintaining the temperature constant $\pm 0.01{ }^{\circ} \mathrm{C}$. A Citizen make electronic balance with an accuracy of $\pm 0.0001 \mathrm{~g}$ was used for weight determination. The density values were reproducible $\pm 0.00006 \mathrm{~g} \mathrm{~cm}^{-3}$.

Viscosities were measured using an Ubbelohode type capillary viscometer (Agrwal Scientific Agra), which was calibrated with doubly distilled water, by measuring efflux time using and a stop watch with a resolution of 0.01 second. The average of at least four reading reproducible within accuracy of 0.01 second was taken as the final efflux time.

A digital conductivity meter Systronic 306 with a dipping type conductivity cell having platinized electrodes was used for conductivity measurement. The temperature of solutions was kept constant with the help of a thermostat. The conductivity meter was calibrated with standard $\mathrm{KCl}$ solution. The accuracy of the conductivity meter was $0.01 \mathrm{mS}$ $\mathrm{cm}^{-1}$ during the study. The results were checked for constant reading.

\section{Results and Discussion}

The apparent molar volume $\Phi_{\mathrm{v}}$ of aqueous solution of oxalic acid was calculated from the observed densities of different concentrations using the following standard expression equation (1).

$$
\Phi_{\mathrm{v}}=\frac{\mathrm{M}}{\mathrm{d}_{0}}+\frac{1000\left(\mathrm{~d}_{0}-\mathrm{d}\right)}{\mathrm{d}_{0} \mathrm{c}}
$$

Where $\mathrm{M}$ is the molar mass of solute, $\mathrm{d}$ and $\mathrm{d}_{0}$ are densities of solution and pure solvent, respectively, and $\mathrm{c}$ is the molarity of solute. The values of densities and calculated values are given in Table 1 . The dependence of apparent molar volume on concentration of the solute is given by the equation (2), known as Masson's equation.

$$
\Phi_{\mathrm{v}}=\Phi_{\mathrm{v}}^{0}+S_{\mathrm{v}} \mathrm{c}^{0.5}
$$


Table 1. Variation in density, specific conductance, and $\eta / \eta_{0}$ for different molar concentration of aqueous oxalic acid at $293 \mathrm{~K}$

\begin{tabular}{|c|c|c|c|c|c|c|c|}
\hline $\begin{array}{l}\text { Conc. } \\
\text { mol dm }^{-3}\end{array}$ & $\begin{array}{c}\text { Density } \\
\mathrm{gcm}^{-3}\end{array}$ & $\begin{array}{c}\Phi \mathrm{v} \\
\mathrm{cm}^{3} \mathrm{~mol}^{-1}\end{array}$ & $\eta / \eta_{0}$ & $\eta / \eta_{0}-1 / c^{0.5}$ & $\left(\mathrm{x}_{\mathrm{S}} / \mathrm{x}_{\mathrm{w}}\right)^{0.5}$ & $\begin{array}{l}\eta / \eta_{0}-1 / \\
\left(x_{s} / x_{w}\right)^{0.5}\end{array}$ & $\begin{array}{c}\text { Spec. } \\
\text { Cond. } \\
\mathrm{mS} \mathrm{cm}^{-1}\end{array}$ \\
\hline 0.055 & 1.0006 & 46.4472 & 1.011 & 0.046904 & 0.031464 & 0.349603 & 13.8 \\
\hline 0.11 & 1.003 & 46.4472 & 1.021 & 0.063317 & 0.044609 & 0.470753 & 21.8 \\
\hline 0.165 & 1.0051 & 48.2686 & 1.031 & 0.076317 & 0.054681 & 0.566926 & 29 \\
\hline 0.22 & 1.0076 & 47.3571 & 1.041 & 0.087412 & 0.063246 & 0.648267 & 35.1 \\
\hline 0.275 & 1.01 & 47.1757 & 1.052 & 0.09916 & 0.070852 & 0.733925 & 41 \\
\hline 0.33 & 1.0122 & 47.6614 & 1.062 & 0.107928 & 0.077717 & 0.797762 & 46.2 \\
\hline 0.385 & 1.0148 & 46.9675 & 1.073 & 0.11765 & 0.084083 & 0.868187 & 51 \\
\hline 0.44 & 1.017 & 46.3578 & 1.082 & 0.12362 & 0.09 & 0.911111 & 56.7 \\
\hline 0.495 & 1.0192 & 47.6614 & 1.092 & 0.130763 & 0.095603 & 0.962309 & 61.8 \\
\hline 0.55 & 1.0216 & 47.54 & 1.102 & 0.137537 & 0.100896 & 1.010942 & 64.7 \\
\hline
\end{tabular}

$\mathrm{x}_{\mathrm{s}}=$ mole fraction of solute, $\mathrm{x}_{\mathrm{w}}=$ mole fraction of water

The values of apparent molar volume $\Phi_{v}$ were used for applicability of Masson's equation. The plot of $c^{0.5}$ versus $\Phi_{v}$ was not linear. The variation of $\Phi_{v}$ with $c^{0.5}$ followed a cyclic trend having maxima and minima. This type of trend resembles with the $\mathrm{X}$-ray refraction data on liquids in radial distribution function which is a measure of average particle density as a function of distance from arbitrary origin. Such fluctuations of $\Phi_{v}$ in highly dilute aqueous media at lower concentration were also observed in case of alcohols [14] having protic nature due to the hydroxyl group. The limiting apparent molar volume $\left(\Phi_{\mathrm{v}}^{0}\right)$ was calculated using the least square treatment to the plot of $\Phi_{\mathrm{v}}$ versus $\mathrm{c}^{0.5}$. The plot is given in Figure 1. The value obtained for $\Phi^{0}{ }_{\mathrm{v}}$ and $S_{\mathrm{v}}$ for oxalic acid at $293 \mathrm{~K}$ are $46.618 \pm 0.50-\mathrm{cm} 3$ $\mathrm{mol}^{-1}$ and $1.082 \pm 0.06 \mathrm{~cm}^{3} \mathrm{l}^{1 / 2} \mathrm{~mol}^{-3 / 2}$ respectively. The positive value of $\Phi^{0}{ }_{\mathrm{v}}$ indicating there by a interaction between solute and solvent molecule. The $S_{v}$, indicating that the solute have good solute-solute interaction or good complex ion forming tendency. The oxalic acid ionizes in two steps; first ionization takes place one thousand times than the second.

$$
\begin{array}{lll}
\mathrm{H}_{2} \mathrm{C}_{2} \mathrm{O}_{4} \leftrightharpoons & \mathrm{HC}_{2} \mathrm{O}_{4}^{-}+\mathrm{H}^{+} & \left(\mathrm{K}_{1}=5.4 \times 10^{-2}\right) \\
\mathrm{HC}_{2} \mathrm{O}_{4}{ }^{-} \leftrightharpoons & \mathrm{C}_{2} \mathrm{O}_{4}{ }^{2-}+\mathrm{H}^{+} & \left(\mathrm{K}_{2}=5.2 \times 10^{-5}\right)
\end{array}
$$

The oxalate mono anion formed in first step may form the neutral molecule due to internal hydrogen bond formation through hydroxyl group or it may form hydrogen bond with other mono- oxalate anion. In both the cases the hydrogen bonding justifies the solutesolute interaction as observed in the study.

If we consider that the oxalic acid molecules, mono oxalate anion/ neutral molecule and oxalate ion behave like independent molecule of solute and form molecular assemblies, we can apply the Staurdinger equation (5) to the measured viscosity data of oxalic acid given in Table 1.

$$
\left(\eta / \eta_{0}-1\right) \quad=\mathrm{knc}
$$

Where $\mathrm{k}$ is the characteristic constant, $\mathrm{n}$ is the monomer present in the molecular assemblies and $\mathrm{c}$ is mole concentration of solute. The plot (Figure 2) of concentration versus $\left(\eta / \eta_{0}-1\right) \quad$ is linear with the slope value $0.183 \mathrm{dm}^{3} \mathrm{~mol}^{-1}$. 


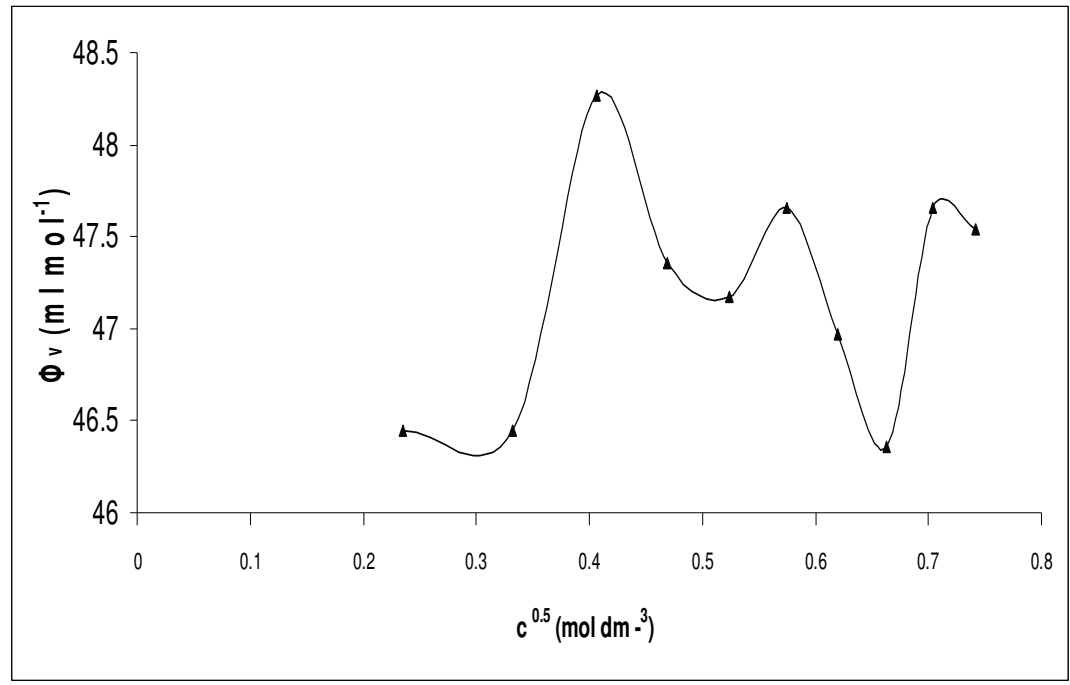

Figure 1. Plot of $\Phi_{\mathrm{v}}$ versus $\mathrm{c}^{0.5}$

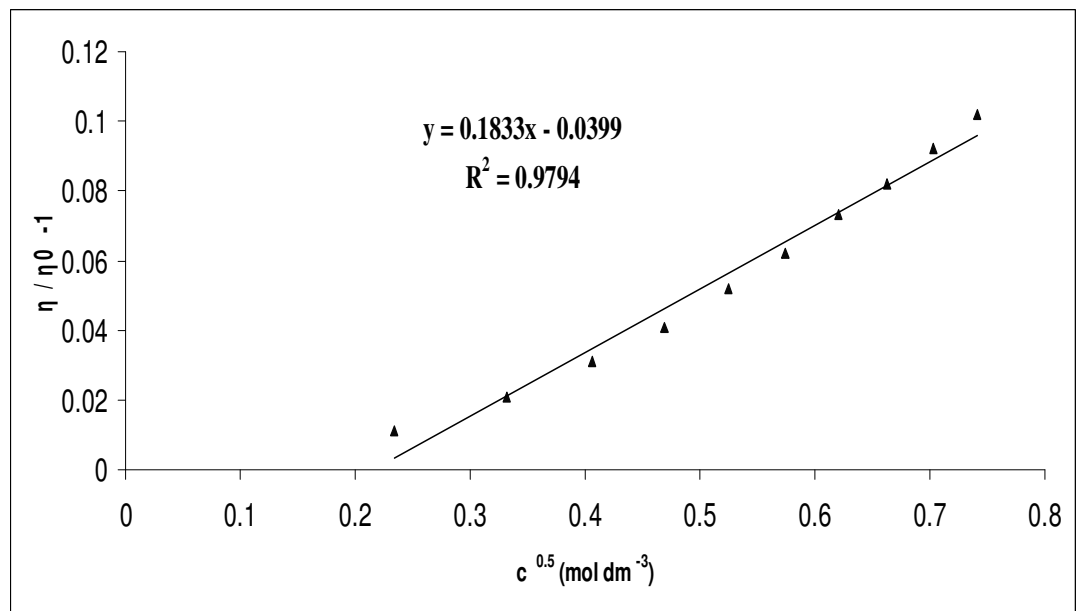

Figure 2. Plot of concentration versus $\left(\eta / \eta_{0}-1\right)$

The values of $\eta / \eta_{0}$ obtained at different concentration were utilized for the determination of intermolecular interactions in aqueous solution. The interaction parameters were obtained with the help of Jone-Dole equation.

$$
\frac{\left(\eta / \eta_{0}-1\right)}{\mathrm{c}^{0.5}}=\mathrm{A}+\mathrm{B} \mathrm{c}^{0.5}
$$

Where, $\mathrm{A}$ and $\mathrm{B}$ are the coefficients for the ion-ion and ion-solvent interactions respectively and $\mathrm{c}$ is the molar concentration. The value of $\mathrm{A}$ and $\mathrm{B}$ were obtained from the intercept and slope of the linear plots of $\left(\eta / \eta_{0}-1\right) / c^{0.5}$. The obtained values of intercept and slope are given in Figure 3. 


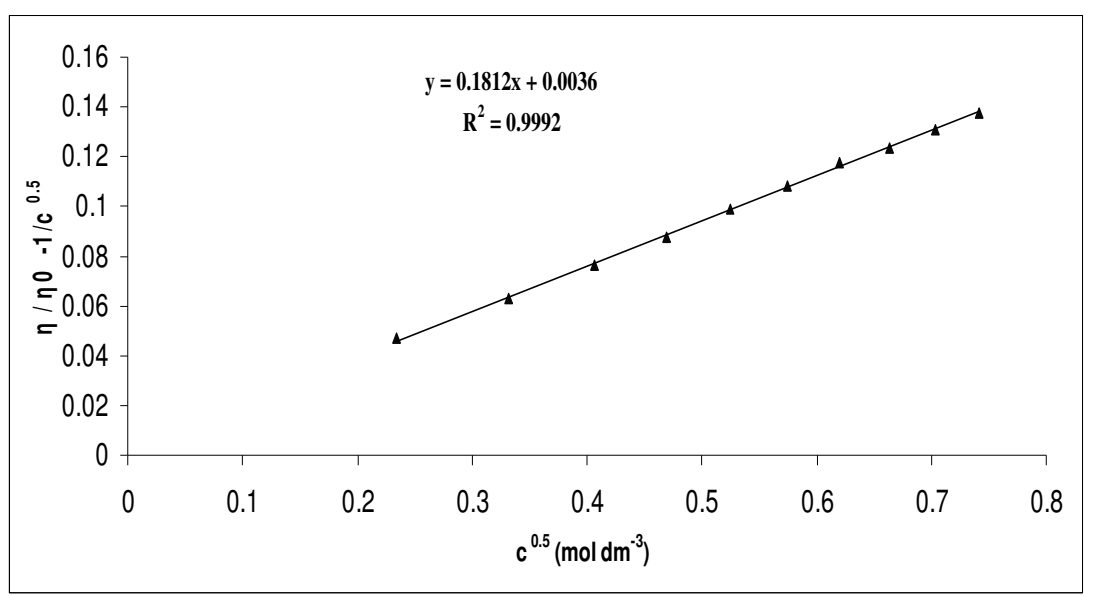

Figure 3. Linear plot of $\left(\eta / \eta_{0}-1\right) / c^{0.5}$

The values of concentration were used to calculate $\mathrm{x}_{\mathrm{s}}$ and $\mathrm{x}_{\mathrm{w}}$ and data obtained are recorded in Table 1.The linear plot $\mathrm{x}_{\mathrm{s}} / \mathrm{x}_{\mathrm{w}}{ }^{0.5}$ versus $\eta / \eta_{0}-1 / \mathrm{x}_{\mathrm{S}} / \mathrm{x}_{\mathrm{w}}{ }^{0.5}$ confirm the validity of modified Jone-Dole equation as given below.

$$
\eta / \eta_{0}-1 /\left(\mathrm{x}_{\mathrm{s}} / \mathrm{x}_{\mathrm{w}}\right)^{0.5}=\mathrm{A}_{\mathrm{x}}+\mathrm{B}_{\mathrm{x}}\left(\mathrm{x}_{\mathrm{s}} / \mathrm{x}_{\mathrm{w}}\right)^{0.5}
$$

Where $A_{x}$ and $B_{x}$ are the coefficient, which are the measure of the interactions present between solute-solute and solute-solvent. The plot is given in Figure 4 with slope and intercepts values.

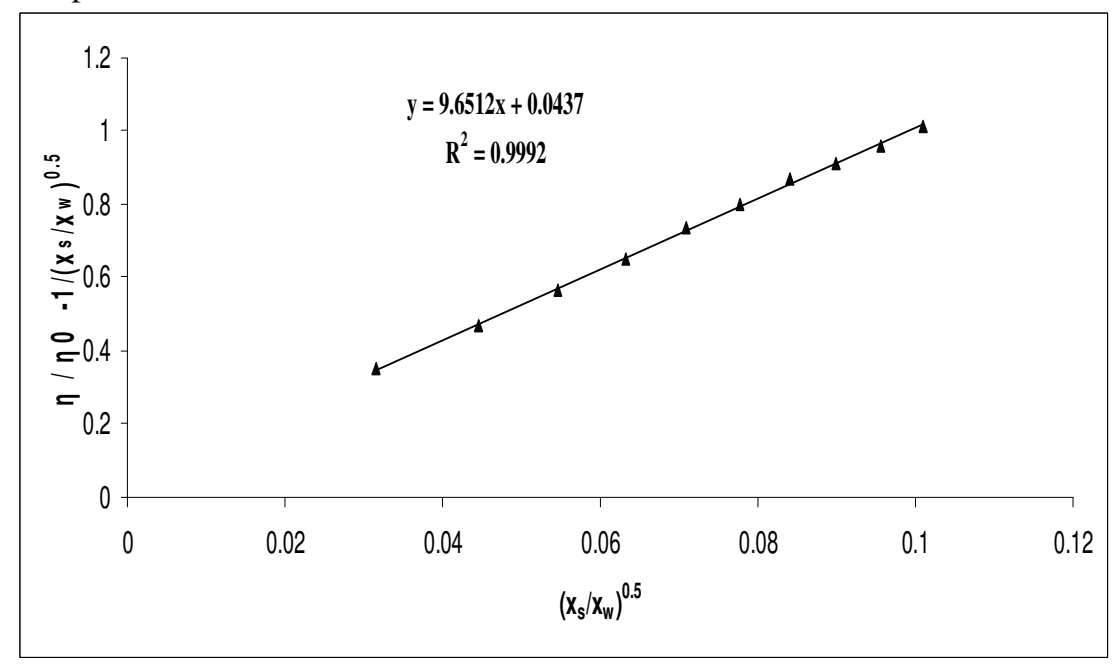

Figure 4. Plot $\mathrm{x}_{\mathrm{s}} / \mathrm{x}_{\mathrm{w}}{ }^{0.5}$ versus $\eta / \eta_{0}-1 / \mathrm{x}_{\mathrm{s}} / \mathrm{x}_{\mathrm{w}}{ }^{0.5}$

The values of $A, A_{x}, B$ and $B_{x}$ obtained in the study are positive which show the presence of ion-solvent interactions and solute-solute/ion-ion interaction. In dilute aqueous oxalic acid solution. The positive value of coefficient $B$ also indicates that the oxalic acid behaves as structure maker in highly dilute aqueous solution. The value of A is very small which indicates the possibility of solute-solute interaction is very small in comparison to the 
inter molecular attraction between solute and solvent. It suggests the internal hydrogen bond formation in mono oxalate anion. The concentration range used in the study was optimum for the validity of Staurdinger, Jone-Dole equation and Modified Jone- Dole equation in which it acts as structure maker. Further addition of solute can modify the structure of water by hydration as obtained volumetrically ${ }^{10,11}$ from thermal expansion. The ratio of $\left(B_{x} / B\right)$ is 53.31, which is nearly equal to reported value for sugars ${ }^{1}$.

Although the oxalic acid is a weak electrolyte, in the present study it has been concluded that the solute solvent interactions takes place with small solute-solute interactions. The carboxalate ion has resonating structure and hydrogen bond forming capability. To investigate the existence of charged assemblies specific conductance of oxalic acid was measured the data are given in Table 1 .The data were analysed by the Arrhenius -Ostwald relation given by the equation. The plot $c \lambda_{\mathrm{m}}$ versus $1 / \lambda_{\mathrm{m}}$ were linear given in Figure 5 .

$$
\frac{1}{\lambda_{\mathrm{m}}}=\frac{1}{\lambda_{\mathrm{m}}^{0}}+\frac{\mathrm{c} \underline{\lambda}_{\underline{m}}}{\lambda_{\mathrm{m}}^{0}} \underline{\mathrm{A}}_{\mathrm{A}}
$$

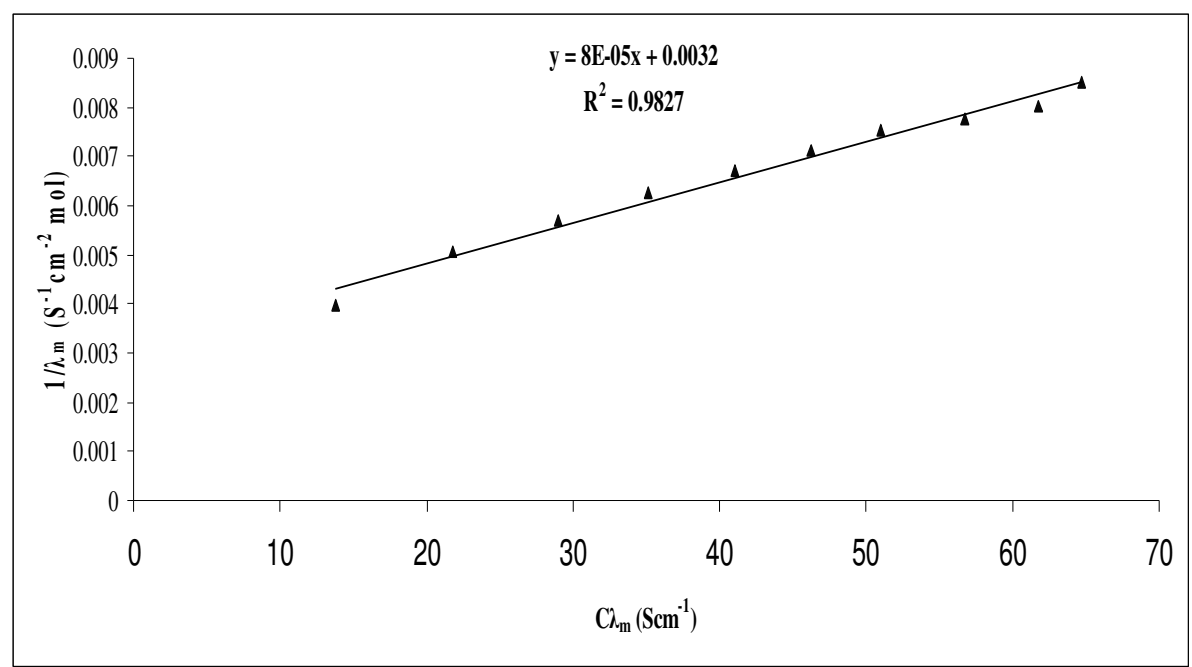

Figure 5. Plot $\mathrm{c} \lambda_{\mathrm{m}}$ versus $1 / \lambda_{\mathrm{m}}$

The value $\lambda^{0}{ }_{\mathrm{m}}$ is $312 \mathrm{~S} \mathrm{~cm}^{-1}$, which is nearly double of ionic molar conductance at infinite dilution of oxalate ion. The value of $\mathrm{K}_{\mathrm{A}}$ has significant value 7.78. The calculated value is also in agreement with the results concluded that the solute-solvent interactions exist in highly dilute aqueous solution of oxalic acid.

\section{Conclusions}

A perusal of results indicates that the B coefficient is positive and fairly large for oxalic acid in the concentration range studied, thereby showing the strong solute-solvent interaction in highly dilutes aqueous solution. This is also evident from the value of $\Phi^{0}{ }_{\mathrm{v}}$. The solvent water and solute oxalic acid has protic solvent characteristics. The dissociation of acid forms mono oxalate anion, having resonating and hydrogen bond forming capacity, which can form various ionic equilibria of association or ionic doublet. The relationship between viscosity data and concentration of solute proposed by Staurdinger for poly molecular assemblies 
has been also observed in the study. The experimental viscosity data is in good agreement with the Jone-Dole and Modified Jone-Dole equation.

\section{References}

1. Mathpal R, Joshi B K, Joshi S and Kandpal N, Monahshefte fur Chemie. 2006, 137, 375.

2. Roga M B, Sidd T M, Baethel J, Neueder R and Apelblat A, J. Soln. Chem. 2002, 31, 1.

3. Zhao C, Ma P and Li J J.Chem. Thermodyn. 2005, 37, 37.

4. Chowdoji Rao K and Brahmji Rao, S Indian J. Chem. 1983, 22A 327.

5. Mandal P K, Seal B K, Chatterji D K and Basu A S, .J. Soln. Chem. 1978, 7, 57.

6. Shubha M C S, Chowdji Rao K and Brahmji Rao S, J Indian Chem. Soc. 1990, 67, 19.

7. Das U N and Mohanty B K, Indian J. Chem.1996, 35A, 1047.

8. Blokhara R L, Kumar S and Kant S, Indian J. Chem. 1990, 29A, 56.

9. Nikam P S and Hiray A R, J. Indian Chem. Soc.1989, 66, 883.

10. Parmar M L, Awasthi R K and Guleria M N, J. Chem. Sci. 2004, 116 (1), 33.

11. Gupta R R and Singh M, Indian J. Chem. 2007, 46A, 455.

12. Parmar M L d Guleria M K, J. Indian Chem. Soc. 2005, 82, 648.

13. Popvych O, Tomkins. R T P, Non Aqueous Solution Chemistry; John Wiley \& Sons, New York 1981, 255.

14. Kaulgud M V, Dhondge S S and Maharie A G, Indian J. Chem. 1995, 34A, 106. 


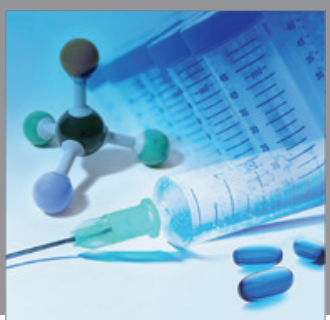

International Journal of

Medicinal Chemistry

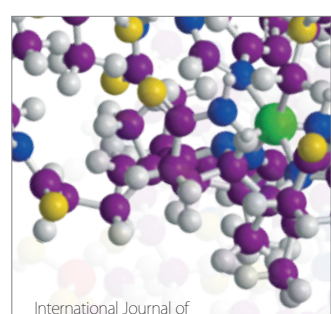

Carbohydrate Chemistry

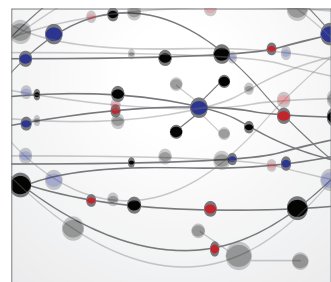

The Scientific World Journal
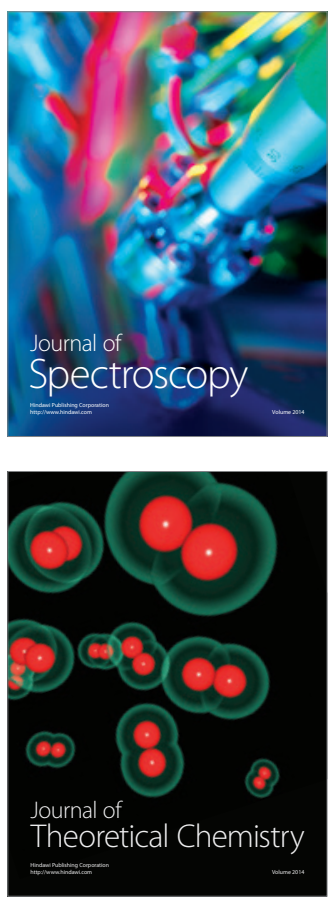
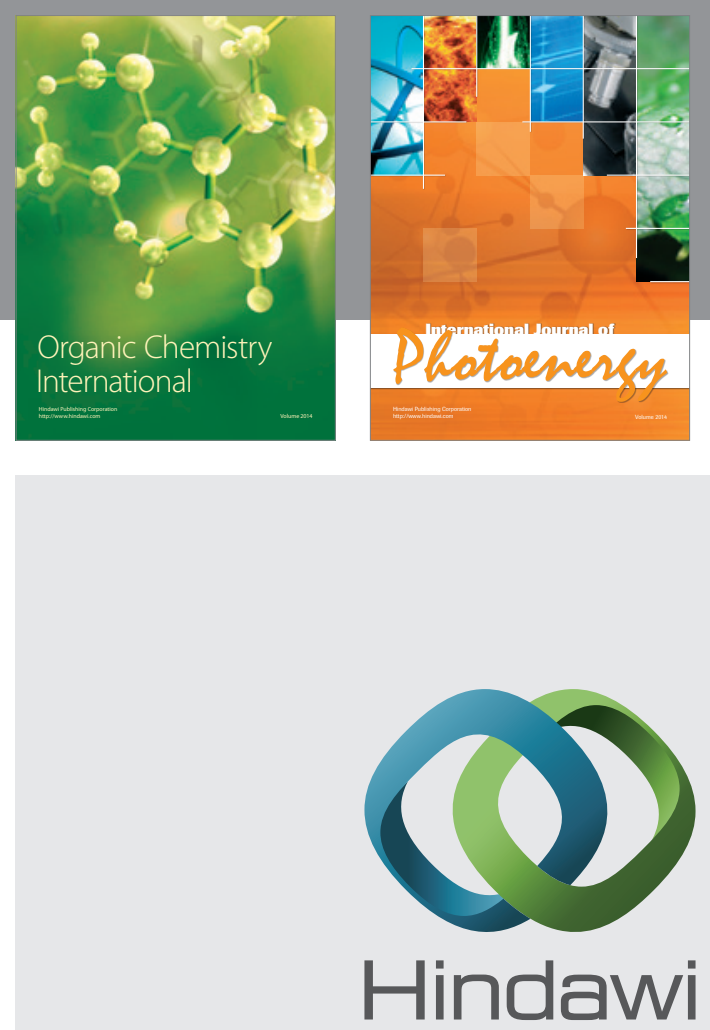

Submit your manuscripts at

http://www.hindawi.com
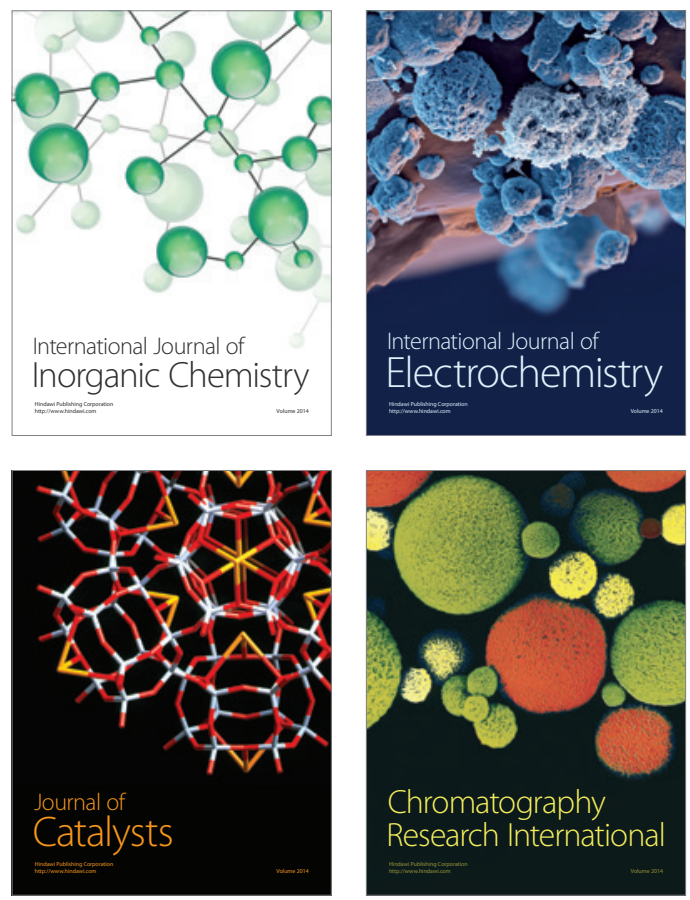
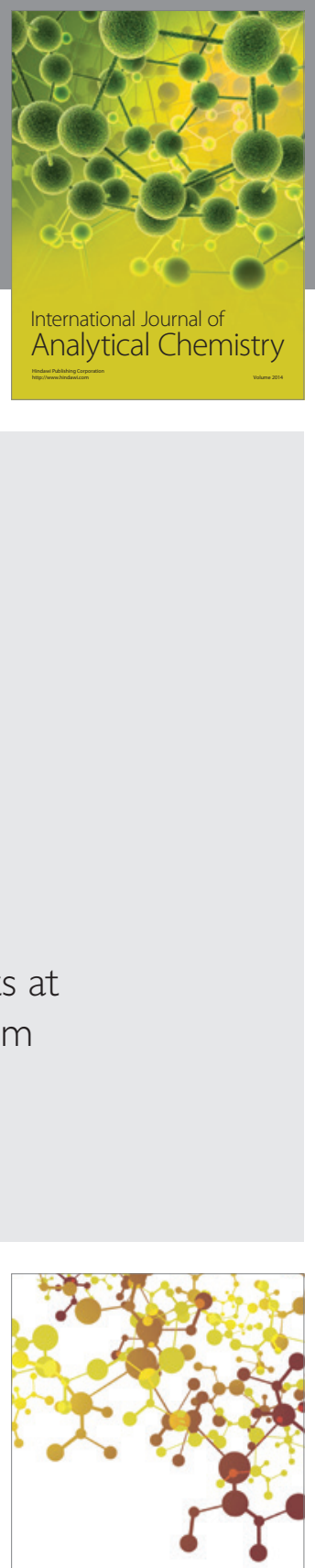

Journal of

Applied Chemistry
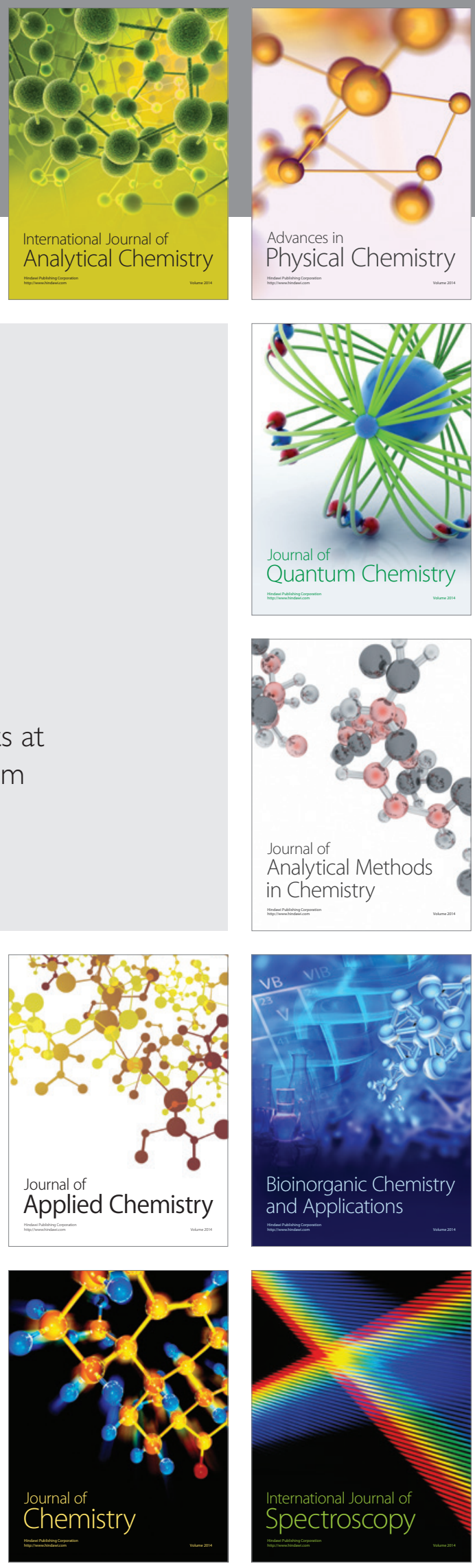